\title{
Analysis of Environmental and Economic Benefits of Integrated Exhaust Energy Recovery (EER) for Vehicles
}

\author{
Zhijun Peng* \\ Department of Engineering and Design, University of Sussex, UK \\ *Corresponding author, z.peng@sussex.ac.uk \\ Tianyou Wang \\ Stake Key Laboratory of Engine, Tianjin University, China \\ Yongling He, Xiaoyi Yang, Lipeng Lu \\ International Energy Research Centre, Beihang University, China
}

\begin{abstract}
Differing from those traditional vehicle exhaust heat recovery systems which just provided thermal energy directly for cabin warming, integrated Exhaust Energy Recovery (EER) which is researched and developed mainly in recent years aims to convert exhaust thermal energy to mechanical or electric energy for increasing the total thermal efficiency and the total power of powertrain. In the study presented in this paper, an analytic model was built for examining the environmental and economic benefits of integrated EER systems. Then the improvement on the total powertrain efficiency and net reduction of $\mathrm{CO}_{2}$ emissions were investigated, in terms of the average vehicle used in the UK. Results show that, for light duty vehicles fitted with thermal cycle EER system, the cost increase could be paid back in 10.1 years and $\mathrm{CO}_{2}$ emission could be paid back in just 1.9 years, compared to Hybrid Electric Vehicle's (HEV's) 11.9 years and 1.4 years for cost and $\mathrm{CO}_{2}$ emission, respectively. When the annual fuel price increase is considered, the cost pay-back is reduced to 8.1 years for EER vehicles and 8.9 years for HEVs. Higher mileage vehicles will have more obvious advantage for fitting EER system. When doubled annual mileage is considered, EER system can reduce the cost and $\mathrm{CO}_{2}$ emission pay-back times to 2.7 years and 0.6 years, compared to HEV's 8.5 and 2.7 years, respectively.
\end{abstract}

\section{KEYWORD}

Exhaust energy recovery, $\mathrm{CO}_{2}$ emission, cost, pay-back time, passenger car

\section{INTRODUCTION}

In recognition of the need to further reduce vehicle exhaust emissions and the greenhouse gas $\mathrm{CO}_{2}$, there has been a quickly increased interest in the development of cleaner and more efficient energy saving vehicle powertrain. When the cost for obtaining even a $1 \%$ increase on the engine combustion efficiency is significant, 
technology innovation around vehicle powertrain has involved more on hybrid configuration (such as Hybrid Electric Vehicles - HEVs) and integrated Exhaust Energy Recovery (EER) in recent years. In the current research, integrated EER refers to those new technologies beyond conventional uses for exhaust waste heat such as turbocharger or cabin air-heating. While HEV technology has achieved considerable market share in recent years, R\&D on EER is being paid more attention, particularly while energy collected by EER can be easily applied on HEVs $[1,2,3]$.

Normally the maximum net brake efficiency of Internal Combustion (IC) engines is difficult to be higher than $42 \%$ [4], large amount fuel energy is rejected from the engine to the surroundings as waste heat in several forms, with a significant fraction through the exhaust. A recent study [5] estimated in a typical 2.0 litre gasoline engine used on passenger cars, $21 \%$ of the released energy is wasted through the exhaust at the most common load and speed range. The fraction increases to $44 \%$ at the peak power point. On average, about one third of energy generated from the fuel is wasted via exhaust gases. Current estimates of waste thermal energy from ground vehicle systems range from $20 \mathrm{~kW}$ to $400 \mathrm{~kW}$, depending on engine size and engine torque-speed conditions. This is equivalent to annually 45 billion gallons of gasoline fuel lost through the exhaust pipes of the 240 million light-duty passenger (LDP) vehicles in USA alone [6].

LDP vehicle exhaust systems operate at gas temperatures from 500 to $900{ }^{\circ} \mathrm{C}$, typically between 600 and $700{ }^{\circ} \mathrm{C}$. For Heavy-Duty (HD) vehicles, exhaust gas temperatures range from 500 to $650{ }^{\circ} \mathrm{C}$ under general driving condition. These can be further boosted during periodical regenerations of diesel particulate filter (DPF) and other aftertreatment advices [7]. Those high exhaust temperatures provide significant opportunities for EER to generate energy for increasing powertrain's efficiency [6, 8].

Differing from conventional exhaust energy utilising technologies such as turbocharger, cabin air-heating [9, 10], desalination [11] and reducing engine warm-up time [12], integrated EER which has been mainly focused in recent years mainly include thermal cycle system based on Rankine Cycle (RC) and Thermoelectric (TE) regeneration. The latter can directly convert part of the exhaust heat to electric power through the thermoelectric phenomenon, without the use of mechanically rotating parts, and providing some advantages such as compact package, without noise and vibration, and high reliability. However, there exist significant system design challenges during the development of TE system due to its low conversion efficiency and relatively high costs of thermoelectric semiconductor materials $[13,14]$.

So far, turbochargers and recently developed other turbo-compounding systems have been selected as the first option for most exhaust waste energy recovery of IC engines. However, as the increase of exhaust back pressure caused by the turbine of turbocharger or turbo-compounding system, the system efficiency is limited, compared to RC EER system $[15,16]$. On the other hand, as the turbine always needs necessary pressure ratio, the exhaust gas sensible heat absorbed by turbocharger or turbo-compounding system is constrained and the exhaust temperature from the turbine is always still very high and a lot sensible heat is still contained. This allows a RC EER system still being able to be fitted downstream even a turbocharger or turbo-compounding system has been installed. A RC EER system does not increase the exhaust back pressure obviously. 
Meanwhile, it can absorb much higher fraction of exhaust sensible heat than turbochargers or turbocompounding system if appropriate heat exchanger and other RC hardware are designed.

The conversion of exhaust heat energy into useful power by integrated EER system would not just bring measurable advantages for improving fuel consumption but also increase engine power output (power density) or vehicle downsizing, further reducing $\mathrm{CO}_{2}$ and other harmful exhaust emissions correspondingly. It was predicted by Vazaquez et al. [17] that if only $6 \%$ of the heat contained in the exhaust gases were converted to electric power for replacing the output of alternator, this would mean reduction of fuel consumption by $10 \%$ due to the decrease in mechanical losses from the resistance of the alternator drive. In addition, the experimental work conducted by Honda [18] with a thermal recovery system showed a maximum thermal cycle efficiency of $13 \%$ could be achieved. At $100 \mathrm{~km} / \mathrm{h}$ vehicle speed which needs approximately $19.2 \mathrm{~kW}$ engine powers, the thermal recovery system can yield a power output of $2.5 \mathrm{~kW}$, representing an increase in the thermal efficiency of the engine from $28.9 \%$ to $32.7 \%$.

When the benefit on fuel cost and emission reductions provided by EER have been approached more or less, its economic benefit has not been depicted clearly. For promoting the development of EER systems and its commercialization, it is necessary to provide necessary information about its pay-back times of both cost and carbon emissions. In this paper, average EER efficiency based on New European Driving Cycle (NEDC) would be estimated by investigating recoverable exhaust sensible heat of a light duty gasoline powertrain. Then the environmental and economic benefits of EER vehicles will be analysed by considering average driving condition in the UK.

\section{EER EFFICIENCY ANALYSIS}

As the system efficiency of thermoelectric material EER system is still very low but the price is high compared to thermal cycle EER systems, the concentration of this research is put on thermal cycle EER systems based on Rankine Cycle. As shown in Figure 1, a Rankine Cycle EER system for vehicles can be designed with mechanical connection for power transfer between the EER system and the vehicle powertrain. The EER system should physically comprise four main components: evaporator/heat exchanger, expander, condenser and circulation pump.

With the evaporator/heat exchanger, the working fluid is superheated by absorbing thermal energy provided from the exhaust gas. Flowing out from the evaporator as high temperature steam, the working fluid is driving the expander to produce useful work. Then the waste steam from the expander will be cooled down through the condenser to return to liquid phase. In the next step, the working fluid is pumped to maintain the circulation.

For most internal combustion engines, there is approximately $20-40 \%$ of total fuel energy which is dissipated through exhaust gas, with the majority as sensible enthalpy due to high exhaust temperature and the minority as chemical enthalpy due to incomplete combustion. To evaluate possible energy amount which can be recovered 
by EER system, it is necessary to obtain the exhaust temperature characteristics under different driving conditions. In the current research, a 1.4 litre light-duty gasoline engine used for powering passenger car has been selected for the analysis. Main specifications of the test engine can be found in Table 1 and the exhaust gas temperature variation as function of engine speed and load can be found in Figure 2. It should be noted those exhaust temperatures were measured just at the entrance of the EER heat exchanger. The engine operation process for those measurements followed the order of fuel loops. At a specified engine speed, the full load point was recorded at first. Then the engine load was reduced with appropriate step, until the load close to the idle operation. By repeating the fuel loop process with different engine speeds, the full maps of exhaust temperature was achieved. When those measurements were carried out, the existence of the EER heat exchanger might have more and less influence for increasing exhaust back pressure. Then the exhaust temperature might have a little increase, compared to the original engine without an EER system.

In Figure 2, it can be found that under peak power area, the engine has the highest exhaust temperature over $800^{\circ} \mathrm{C}$ which is indubitably very suitable for EER. But for passenger cars, normally the engine just operates part load with speed between $1500 \mathrm{rpm}$ and $3000 \mathrm{rpm}$ (for gasoline engines) and torque between 20\% and 50\% of full load torque. In the operating range, the exhaust temperature is just between $400^{\circ} \mathrm{C}$ and $650^{\circ} \mathrm{C}$ and the EER system efficiency and recoverable energy amount under this condition would be mainly examined.

Based on exhaust gas analysis to find amounts of main component $\left(\mathrm{H}_{2} \mathrm{O}, \mathrm{CO}_{2}, \mathrm{O}_{2}, \mathrm{~N}_{2}\right)$ in the exhaust gas under different operating condition, the exhaust sensible heat $q_{\text {exh }}$ can be estimated by summing up each gas component's specific enthalpy. The fraction of exhaust heat $q_{\text {exh }}$ in the total fuel energy could be given by:

$$
x_{e x h}=\frac{q_{e x h}}{h_{f} \dot{m}_{f}}
$$

where $h_{f}$ is the fuel heating value and $\dot{m}_{f}$ is the fuel mass flow rate, respectively.

With the above definition, the fraction of exhaust heat in the total fuel energy is produced for the test engine and the result is plotted in Figure 3.

In this research, the EER Rankine Cycle efficiency $\eta_{R C}$ is defined as the useful work output from the Rankine Cycle to the total sensible exhaust heat, expressed as:

$$
\eta_{R C}=\frac{q_{e v} \eta_{\exp }-w_{p u m p}}{q_{e x h}}
$$


where $q_{e v}$ is the heat energy provided by the evaporator (the heat exchanger) to the expander. $\eta_{\exp }$ is the working efficiency of the expander and $w_{\text {pump }}$ is the work consumed by the pump of working fluid in the EER system, respectively.

Then the fraction of the net output work from EER Rankine Cycle in the total fuel energy can be expressed as:

$$
x_{E E R}=x_{e x h} \eta_{R C}
$$

This fraction is considered as the EER efficiency in the current research when the energy lost from the expander to the energy final use was not taken into account. The map of the EER efficiency for the test engine is shown in Figure 4.

From Figure 4, it can be seen, though the maximum EER system efficiency can be up to $14 \%$, in the general operating range of passenger car engines, the value is between $1 \%$ and $10 \%$ for the test engine in the present research. Based on New European Driving Cycle (NEDC), it is estimated approximately 3.9\% of fuel energy can be recovered by the thermal cycle EER system for the test engine. This is equivalent approximately $17.5 \%$ fuel saving for the test engine which has an approximately $22.3 \%$ total engine efficiency under NEDC.

Considering the possible loss for transferring the EER work to the vehicle powertrain system, the net EER efficiency can be around $20 \%$ for the powertrain used in the current research. Combined those EER efficiency data presented in last section, $20 \%$ could be an appropriate figure for representing most EER systems which will be used on passenger cars. This figure will be used for the following section for estimating the cost and carbon emissions of EER vehicles (vehicles fitted with EER system) and their pay-back times of cost and carbon emissions, though it is understood that there is some difference for the efficiency for different vehicles regarding their powertrain configurations and operating conditions.

\section{ANALYSIS OF COST AND CO $\mathrm{CO}_{2}$ EMISSIONS OF EER VEHICLES}

After the EER system efficiency is estimated, environmental and economic benefits of EER vehicles can be analysed. In addition to compare EER vehicles (vehicles fitted with EER system) with pure Internal Combustion Engine (ICE) vehicles, Hybrid Electric Vehicles (HEVs) and HEV+EER vehicles are also considered, while EER system can be electrically connected with HEV for its work output. Powertrain system setup of two configurations of HEV and HEV+EER can be used as shown in Figure 5. 
In Figure 5, the power contribution from different energy sources are represented as the shape size. For example, from HEV to HEV+EER, the engine can get further downsizing. Then the engine size and fuel tank size become smaller and the battery size of HEV+EER gets bigger.

In Figure 6, it shows total cost variations with used years for ICE vehicles, EER vehicles, HEVs and HEV+EER vehicles. Those results are achieved from an analysis based on vehicles sold and used in the UK where the average new passenger car price is approximately $£ 27500$ in 2011 . For HEV, 20\% higher average price is added by considering the actual cost of HEVs in the current market. Those data come from DivenData whose published data can be found at www.drivendata.co.uk. For EER vehicles, the cost increase of $10 \%$ is estimated by including costs of all mechanical hardware (evaporator, expander, condenser, pump and gearbox) and control system. For HEV+EER vehicles, only $25 \%$ average cost increase rather than $30 \%$ (20\% for HEV and $10 \%$ for EER) is added since the electrical work output of EER system could be easily implemented compared to EER mechanical work output configuration.

The annual average cost of vehicles is calculated by including fuel, service, annual authority inspection (in the UK this is named as MOT - Ministry of Transport), insurance and tax. For vehicles used in the UK, the fuel cost is based on the average annual mileage of 12000 miles for the first year new cars, 10000 miles the second year and 8000 miles per year for the following years [19]. ICE vehicles' average fuel consumption is currently about 0.09 litre/mile, compared to 40\% of HEV's saving which was reported by NREL (National Renewable Energy Laboratory) [20] and Ting et al. [21]. From the study in the last section, EER's 20\% saving on fuel consumption is selected. Combining HEV's and EER's individual savings, 50\% saving is assumed for HEV+EER in the present analysis. With regard to the average fuel cost, the current price $£ 1.40 /$ litre in the UK market is used for the calculation. For other annual costs, tax exemption but increased service cost for HEV vehicles are considered.

Then cumulative $\mathrm{CO}_{2}$ emissions and cumulative cost can be formulated as:

$$
C O_{2-\text { cumulative }}=C O_{2-\text { embedded }}+S_{\text {cumulative }} \times F C \times \rho_{\text {fuel }} \times x_{c} \times 44 / 12
$$

Where $S_{\text {cumulative }}$ is the cumulative mileage. FC is the fuel consumption (litre/mile). $\rho_{\text {fuel }}$ is fuel density ( $\mathrm{kg} /$ litre). $x_{c}$ is carbon content rate of fuel. 44 and 12 are the molecular weight of carbon dioxide and that of carbon, respectively.

$$
\text { Cost }_{\text {cumulative }}=\text { Cost }_{\text {embedded }}+S_{\text {cumulative }} \times F C \times P_{\text {fuel }}+\sum_{0}^{n}(\text { Ins }+ \text { Tax }+M O T+\text { Service })
$$

Where $P_{\text {fuel }}$ is fuel price (pound/litre) and Ins represents annual insurance cost, respectively. 
In Figure 6, it can be found that with fixed fuel price, the saving on fuel cost from HEV vehicles could not pay back the cost increase in 10 years due to the high purchase cost. With further estimate, the cost pay-back time for HEV vehicles is about 11.9 years. For EER vehicles, it roughly needs 10.0 years for paying back the cost increase. It suggests EER vehicle would probably be a more attractive option than HEV vehicle for customers, if their concerns are more on the vehicle and operating costs, rather than the fuel saving or carbon emission reduction. When customers make an estimate for the total vehicle cost (purchase cost and operating cost), the current fuel price is always cited since the future of fuel price is always difficult to predict. Therefore, from the analysis shown in Figure 6, it can be assumed that EER vehicles could be promoted for the purpose of fuel or carbon emission saving, at least compared to HEV vehicles. As EER vehicles may be more popular than HEV vehicles, their possible high market share would be helpful to get more $\mathrm{CO}_{2}$ emission reduction, although EER vehicles' fuel saving rate is lower than HEV vehicles.

The estimated pay-back times of various vehicles for $\mathrm{CO}_{2}$ emissions are shown in Figure 7. The average embedded $\mathrm{CO}_{2}$ emissions from vehicle production were estimated with the simple calculation method initially proposed by Berners-Lee [22]. But his figure of $720 \mathrm{~kg} \mathrm{CO}_{2}$ per $£ 1000$ car price was replaced by what Ricardo published $350 \mathrm{~kg} \mathrm{CO}_{2}$ per $£ 1000$ car price [23]. In Figure 7, it can be seen, with HEV vehicle’s big saving rate, it could pay-back $\mathrm{CO}_{2}$ emissions in just 1.4 years. EER need approximately 1.9 years to pay back $\mathrm{CO}_{2}$ emissions. Because of a higher embedded $\mathrm{CO}_{2}$ amount, $\mathrm{HEV}+\mathrm{EER}$ has a similar $\mathrm{CO}_{2}$ pay-back time as EER, though it has a fast pay-back rate. By 5 years (46000 miles), an EER vehicle could save approximately 1.1 tonnes $\mathrm{CO}_{2}$ in average, compared to HEV's average saving of 2.6 tonnes per vehicle and HEV+EER's average saving of 2.7 tonnes. By 10 years $(86000$ miles), the average $\mathrm{CO} 2$ saving per EER vehicle could be approximately 2.8 tonnes $\mathrm{CO}_{2}$, compared to HEV's average saving of 6.2 tonnes and HEV+EER's average saving of 7.0 tonnes.

In Figure 8, it shows the pay-back times when the increase of fuel price is taken into account. Considering the average fuel price increase of $8 \%$ in the UK in last ten years, both EER vehicles and HEV vehicles' pay-back times for cost are reduced to 8.1 years and 8.9 years. HEV+EER has a similar cost pay-back time as HEV, because HEV+EER has higher embedded cost but a higher cost pay-back rate.

In Figure 9, the analysis shows the cost pay-back times for EER vehicles could be significantly reduced to 2.7 years, if doubled mileages (24000 miles for the first year, 20000 miles for the second year and 16000 miles per year for following years) is used, compared to the average mileage used for the previous analysis. It should be noted average fuel consumptions used in this part are still same as used in the previous analysis for those four vehicle configurations, such as 0.09 litre/mile for ICE vehicles. As those high mileage operations involve more motorway driving, HEV's fuel saving rate is faded due to reduced brake regeneration etc. But EER's saving rate can be enhanced (as shown in Figure 4). Results shows HEV still needs at least 8.5 years for cost pay-back. But EER vehicles only need 2.7 years for cost pay-back. For this category of customers, EER vehicles would obviously be a more popular option. 
In Figure 10, it shows EER vehicles with high mileage driving have also obvious advantage of $\mathrm{CO}_{2}$ emissions compared to HEVs. By 5 years (92000 miles), EER vehicle's average $\mathrm{CO}_{2}$ emission saving would be approximately 5.2 tonnes, compared to HEV vehicle's less than 2.6 tonnes. This suggests EER vehicles is very worth to develop for cost benefit and carbon emission benefit, in particular for high mileage vehicles.

\section{CONCLUSIONS}

With experimental measurement of exhaust gas temperature and assessment of exhaust sensible heat and its fraction in the total fuel energy, the recoverable energy by a thermal cycle Exhaust Energy Recovery (EER) system based on Rankine Cycle was analysed for achieving EER efficiency of ground vehicles. Then the cost and carbon emission pay-back times of EER vehicles (vehicles fitted with EER system) were examined and compared with Hybrid Electric Vehicles (HEVs) and HEV+EER vehicles, by considering fixed fuel price, variable fuel price and possible high mileage. From those results, the following conclusions have been derived.

- From the individual light duty vehicle model fitted with an Internal Combustion Engine (ICE) powertrain and a Rankine Cycle EER system, the maximum EER efficiency (to the total fuel energy) can be up to $14 \%$ under high engine power condition. During general passenger car driving range, the efficiency is roughly between $1 \%$ and $10 \%$ depending on the engine operating condition.

- Considering average light duty vehicle annual mileage, fuel price, other subsistence costs (such as insurance, service, tax etc.) in the UK market, an EER vehicle needs 10.1 years for cost pay-back and 1.9 years for carbon emission pay-back, compared to HEV's 11.9 year for cost pay-back and 1.4 year for carbon emission pay-back.

- When $8 \%$ annual fuel price increase is considered, the cost payback for EER vehicles is 8.1 years, compared to HEV's 8.9 years.

- Increased mileage due to more motorway driving would obviously reduce cost and carbon emission payback time for EER vehicles due to high EER efficiency for motorway driving. But for HEV vehicles, similar result would be difficult to achieve due to faded advantage of HEV vehicles on motorway.

\section{ACKNOWLEDGEMENT}

Financial supports from the MoE (Ministry of Education of China) via Programme 111 are gratefully acknowledged.

\section{REFERENCES}


1. Taylor A.M.K.P, Science review of internal combustion engines, Energy Policy, Vol.36:4657-4667, 2008.

2. Wang T., Zhang Y. and Peng Z., A review of researches on thermal exhaust heat recovery with Rankine cycle, Renewable and Sustainable Energy Reviews, Vol.15(1):2862-2871, 2011.

3. Tzeng S. C., Huang K. D., Chen C. C., Optimization of the dual energy-integration mechanism in a parallel-type hybrid vehicle, Applied Energy, Vol.80:225-245, 2005.

4. Teng H., Regner G. and Cowland C., Waste Heat Recovery of Heavy-Duty Diesel Engines by Organic Rankine Cycle Part II: Working Fluids for EHR-ORC, SAE Paper 2007-01-0543, 2007.

5. Chammas R. E. and Clodic D., Combined Cycle for Hybrid Vehicles, SAE Paper 2005-01-1171, 2005.

6. Hendricks T. J. and Lustbader J. A., Advanced Thermoelectric Power System Investigations for Light-Duty and Heavy Duty Applications: Part I, Proceedings of the 21st International Conference on Thermoelectrics, IEEE, Long Beach, CA, 2002.

7. Teng H., Regner G. and Cowland C., Waste Heat Recovery of Heavy-Duty Diesel Engines by Organic Rankine Cycle Part I: Hybrid Energy System of Diesel and Rankine Engines, SAE Paper 2007-01-0537, 2007.

8. Wang T, Zhang J, Zhang Y, Shu G and Peng Z, Energy Analysis for Recoverable Exhaust Heat in a Gasoline Engine, Sustainable Thermal Energy Management in the Process Industries - SusTEM2011, Newcastle, 25th-26th October 2011.

9. Atan R., Heat recovery equipment (generator) in an automobile for an absorption air conditioning system, SAE Paper 980062, 1998.

10. Zhang L. and Wang L., Performance estimation of an adsorption cooling system for automobile waste heat recovery, Applied Thermal Engineering, Vol.17(12): 1127-1139, 1997.

11. Hung T. C., Shai M. S., and Pei B. S., Cogeneration approach for near shore internal combustion power plants applied to seawater desalination, Energy Conversion and Management, Vol.44: 1259-1273, 2003

12. Kauranen P., Elonen T., Wikstrom L., Heikkinen J., and Laurikko J., Temperature optimisation of a diesel engine using exhaust gas heat recovery and thermal energy storage (diesel engine with thermal energy storage), Applied Thermal Engineering, Vol.30(6-7): 631-638, 2009. 
13. Bass J. C., Campana R. J., and Elsner N. B., Thermoelectric generator for diesel trucks, Proceedings of the 10th International Conference on Thermoelectrics, Cardiff, Wales, 1991.

14. Kobayashi M. et al., Thermoelectric generation and related properties of conventional type module based on Si-Ge alloys, Proceedings of the 15th International Conference of Thermoelectric, 1998.

15. Hountalas D. T., Katsanos C. O., and Lamaris V. T., Recovering Energy from the Diesel Engine Exhaust Using Mechanical and Electrical Turbo-Compounding. SAE Paper 2007-01-1563, 2007.

16. Weerasinghe W. M. S. R. and Stobart R. K., Thermal efficiency improvement in high output diesel engines a comparison of a Rankine cycle with turbo-compounding, Applied Thermal Engineering, Vol.31:1-4, 2010.

17. Vazaquez J., Zanz-Bobi M. A., Palacios R. and Arenas A., State of the art of thermoelectric generators based on heat recovered from the exhaust gases of automobiles, Proceedings of 7th European Workshop on Thermoelectrics, Pamplona, Spain, 2002.

18. Endo T., Kawajiri S, Kojima Y., Takahashi K., Baba T., Ibaraki S., Takahashi T. and Shinohara M., Study on Maximizing Exergy in Automotive Engines, SAE Paper 2007-01-0257, 2007.

19. Car Insurance Information, Average Annual Car Miles UK, available online http://www.car-insuranceinformation.org/average-annual-car-miles-uk.html, accessed on 27 December 2012.

20. NREL, NREL Estimates U.S. Hybrid Electric Vehicle Fuel Savings, available online www.nrel.gov/news/press/2007/518.html, accessed on 27 December 2012.

21. Ting C.-C., Tsai D.-Y., Hsiao C.-C., Developing a mechanical roadway system for waste energy capture of vehicles and electric generation, Applied Energy, Vol.92:1-8, 2012.

22. Berners-Lee M, How bad are bananas?: the carbon footprint of everything, ISBN: 1846688914, London, 2010.

23. Ricardo plc, Ricardo study demonstrates importance of whole life vehicle $\mathrm{CO} 2$ emissions, available online www.ricardo.com/ru-RU/News--Media/Press-releases/News-releases1/2011/Ricardo-study-for-LowCarbon-Vehicle-Partnership-demonstrates-importance-of-whole-life-vehicle-CO2-emissions/, accessed on 27 December 2012. 


\section{FIGURES}

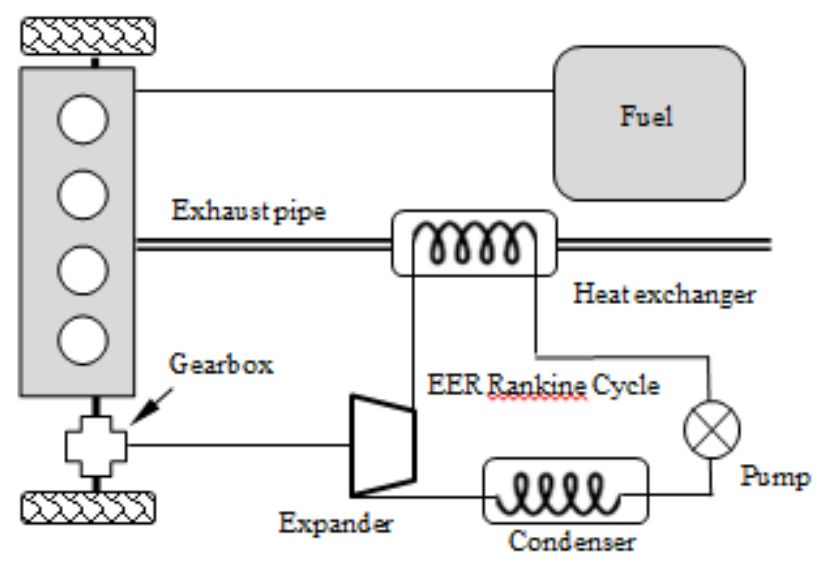

Figure 1 Vehicle EER system with mechanical power output

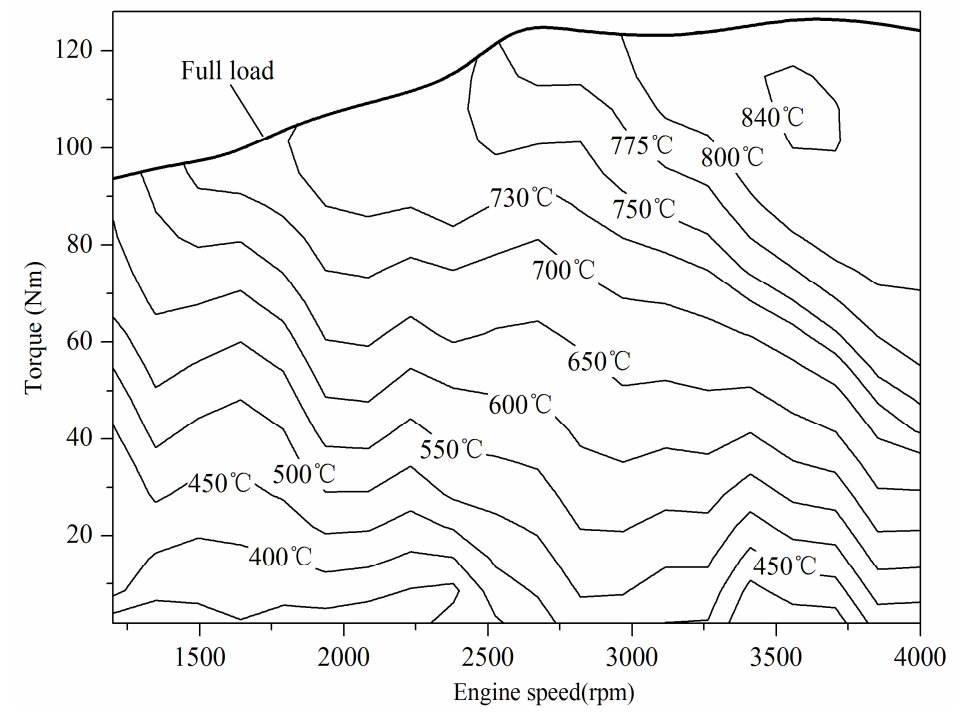

Figure 2 Distribution of exhaust gases temperature of the test engine as function of engine speed and torque 


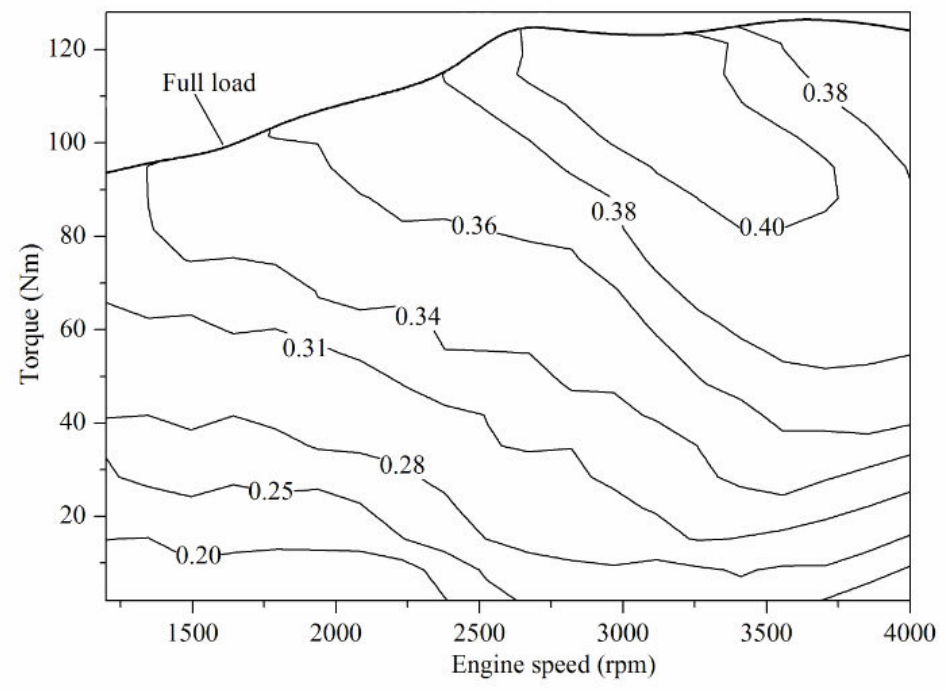

Figure 3 Distribution of the ratio of exhaust sensible heat to the total fuel energy

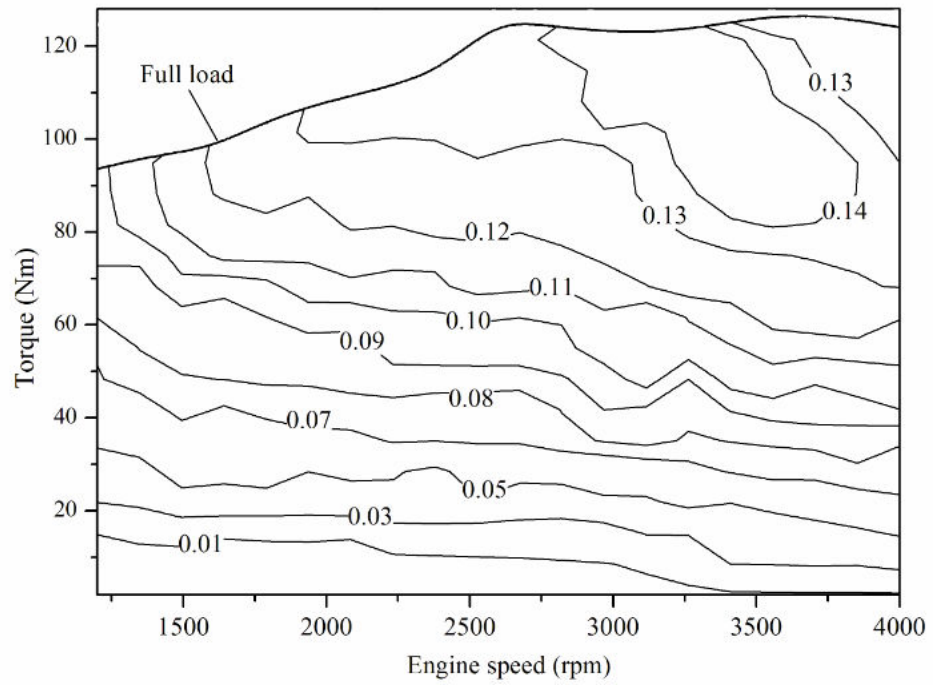

Figure 4 EER system efficiency distributions as function of engine speed and load 


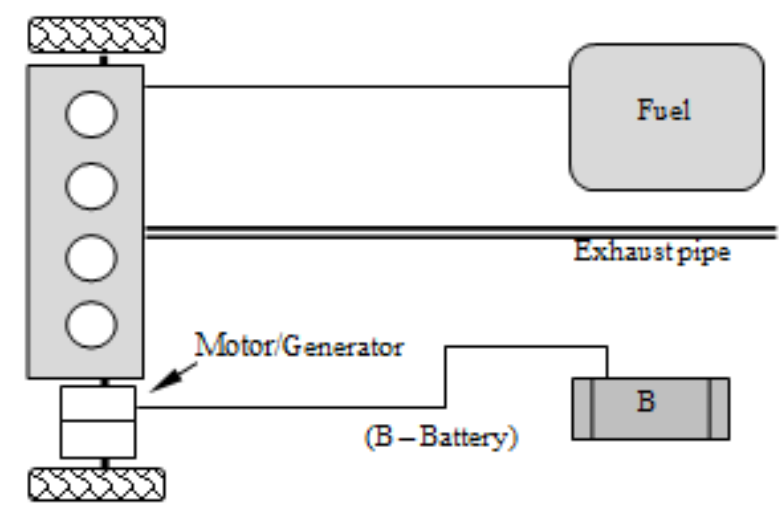

(a)

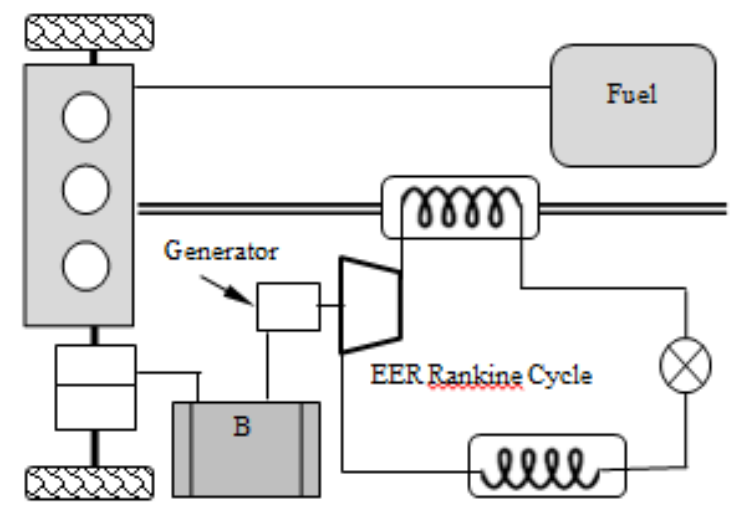

(b)

Figure 5 (a) General HEV system layout; (b) EER system with electrical power output to HEV

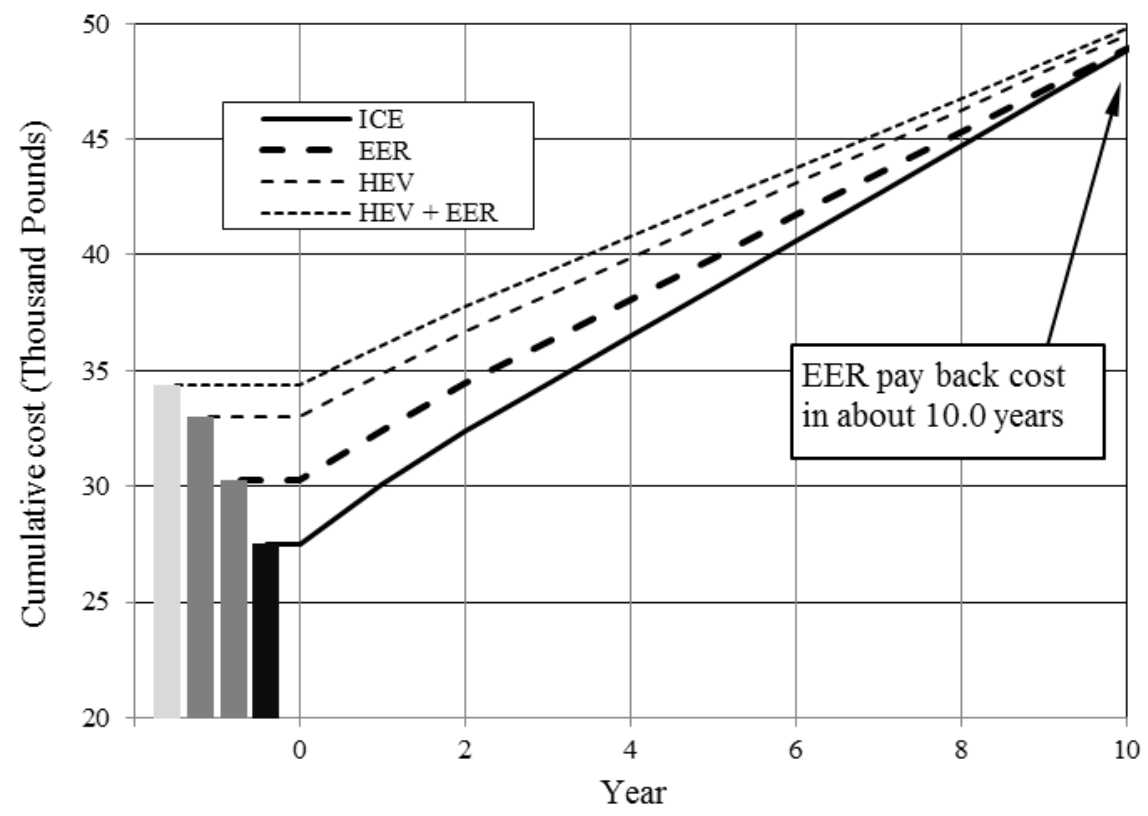

Figure 6 Cost pay-back times for different powertrain configurations 


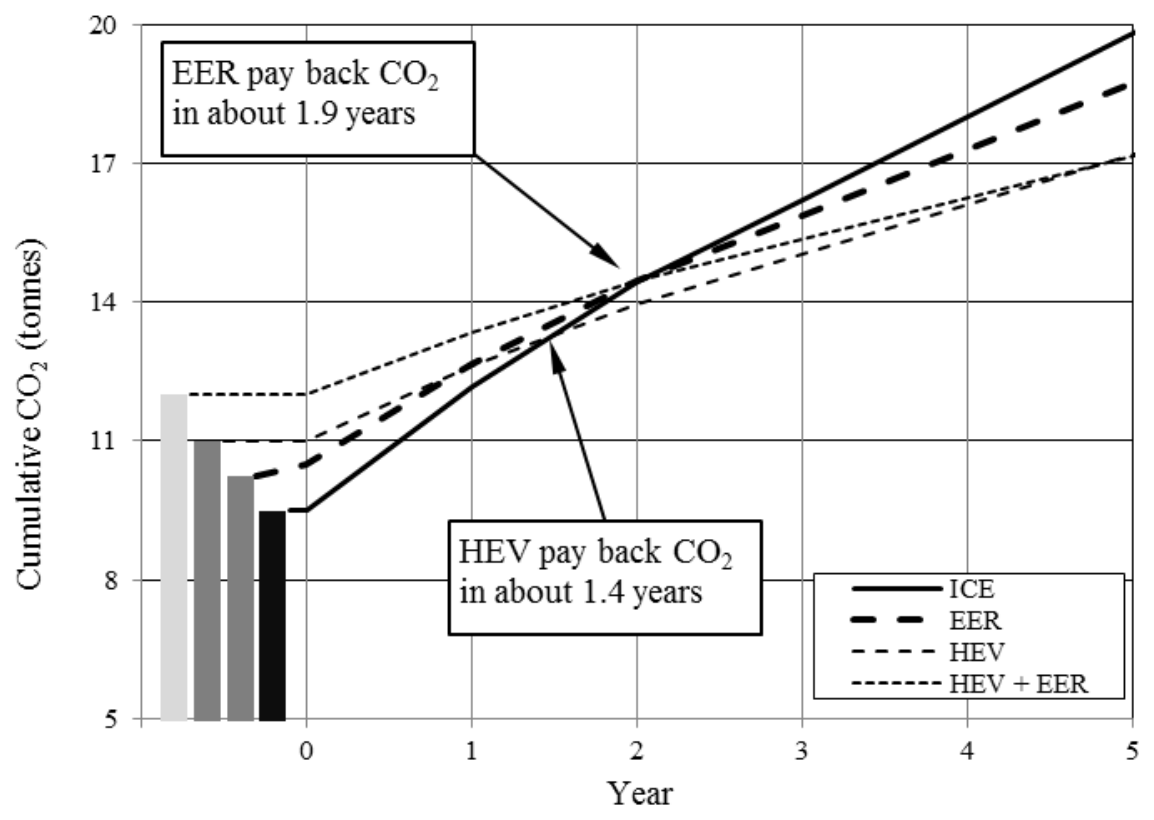

Figure $7 \mathrm{CO}_{2}$ emission pay-back times for different powertrain configurations

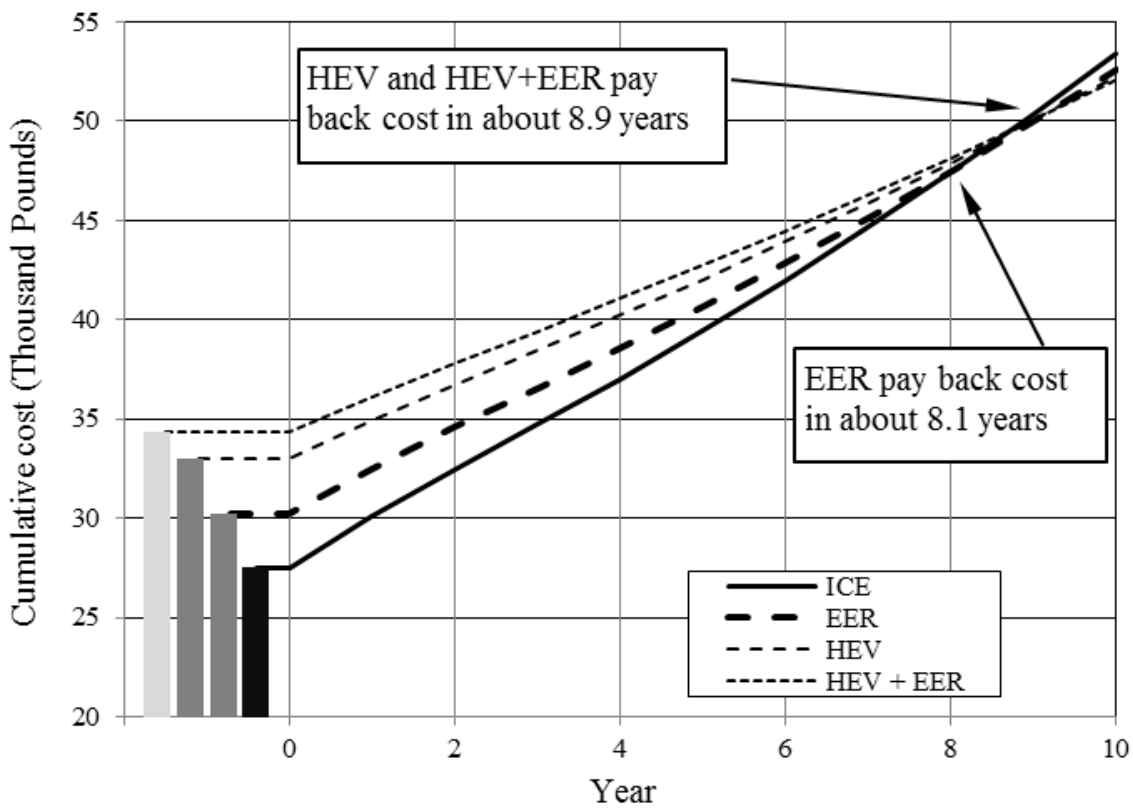

Figure 8 Cost pay-back times of different powertrain configurations with fuel price increase $8 \%$ annually 


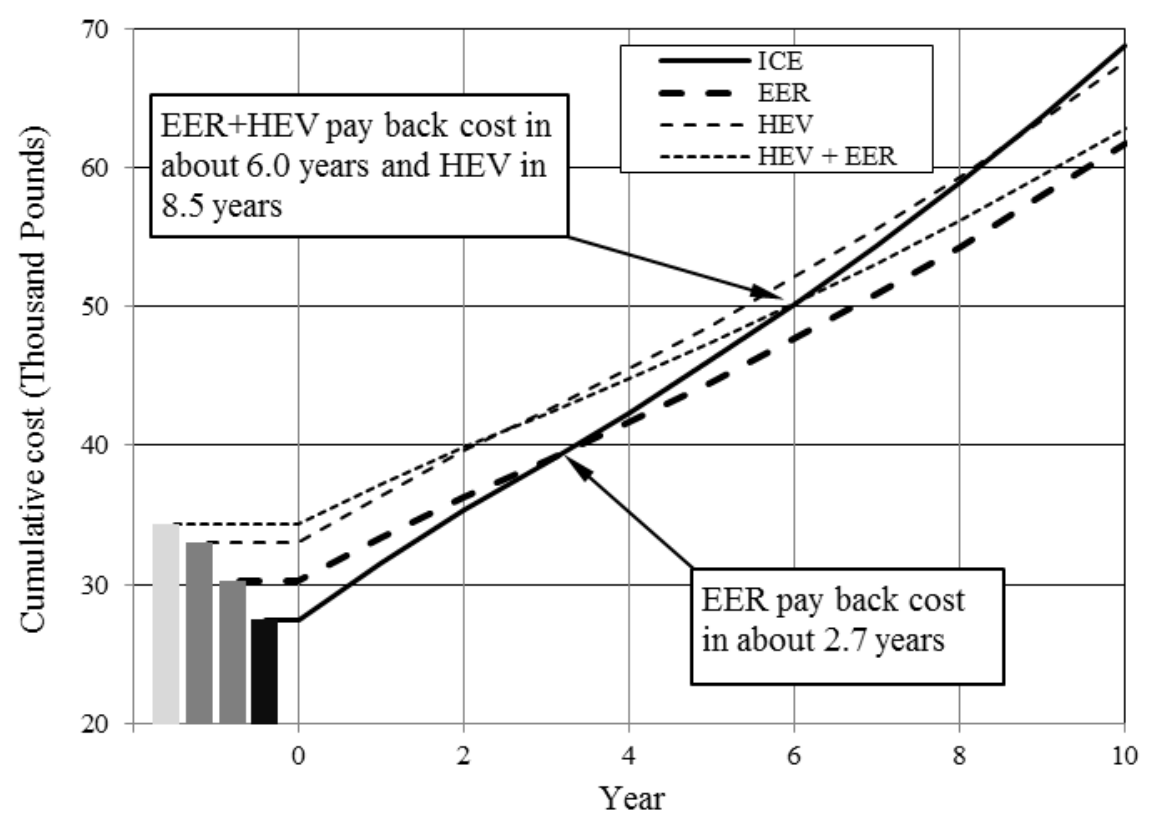

Figure 9 Cost pay-back times of different powertrain configurations with fuel price increase $8 \%$ annually and doubled mileages

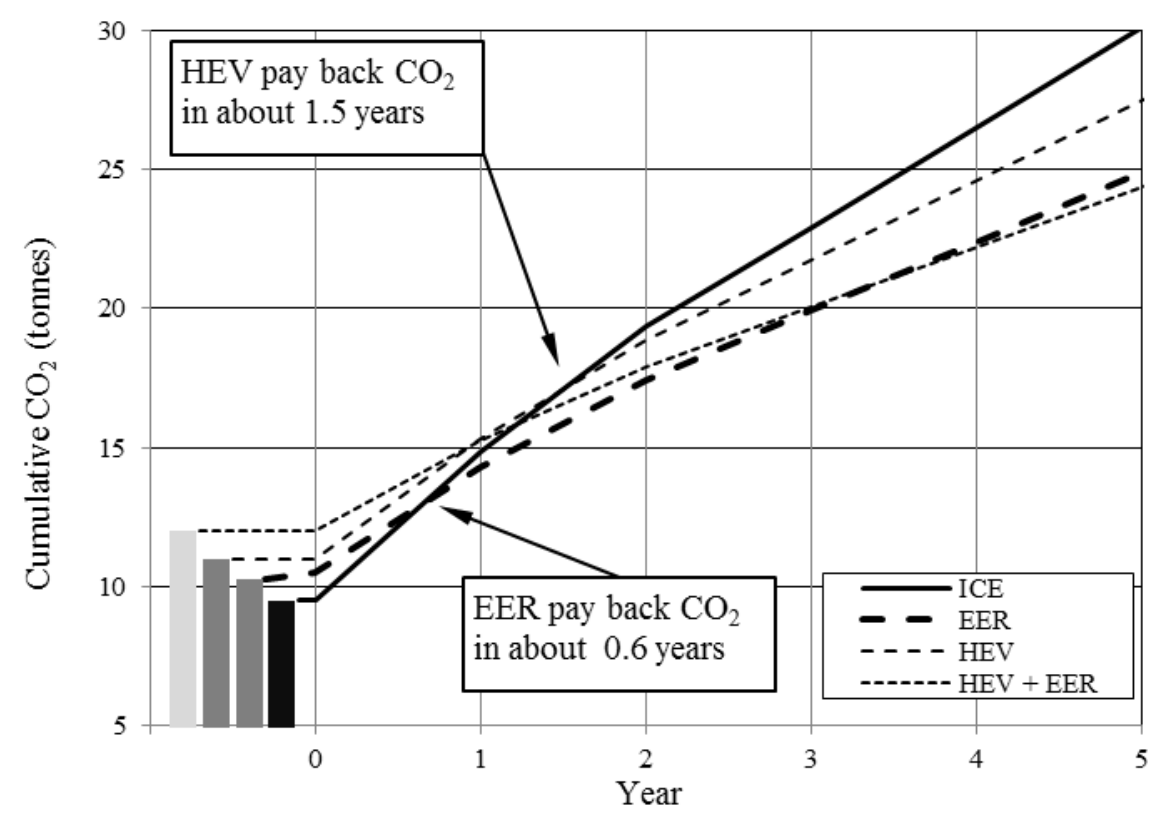

Figure $10 \mathrm{CO}_{2}$ emission pay-back times with doubled mileages 


\section{Tables}

Table 1 Main specifications of the test engine

\begin{tabular}{lr}
\hline Engine type & CA4GA1 \\
Number of cylinders & 4 \\
Bore $\times$ Stroke $(\mathrm{mm})$ & $73 \times 80$ \\
Displacement (L) & 1.339 \\
Compression ratio & 10 \\
Number of valves & 16 \\
Rated power/speed $(\mathrm{kW} / \mathrm{rpm})$ & $67 / 6000$ \\
Maximum torque/speed $(\mathrm{Nm} / \mathrm{rpm})$ & $120 / 4200$ \\
\hline
\end{tabular}

